\title{
Hablar en silencio, decir lo indecible. Una aproximación a la cuestión de los límites del lenguaje en la obra temprana de Martin Heidegger*
}

\author{
PAloma Martínez Matías \\ Albert-Ludwigs Universität Freiburg \\ Philosophisches Seminar \\ Paloma.Martinez@uv.es
}

Resumen: Tras señalar la importancia que el tema del silencio cobra en la reflexión de Martin Heidegger sobre la cuestión del ser, este artículo propone una posible interpretación acerca del sentido que cabría atribuir a este motivo en el despliegue de la analítica existenciaria de Ser y tiempo. Partiendo de un breve estudio de la comprensión del lenguaje expresada en esta obra, nuestro trabajo investiga la íntima vinculación establecida en ella entre el callar del ser-ahí (Dasein) y la llamada "propiedad" (Eigentlichkeit) de su existencia, manifiesta en el contexto del análisis de la angustia y de la voz silenciosa de la conciencia. Más adelante, la hipótesis hermenéutica planteada es puesta en relación con el problema de la indicación formal y con la interpretación heideggeriana del decir poético, fundamentalmente centrada en la poesía de Hölderlin, que se inicia hacia mediados de los años treinta.

Palabras clave: lenguaje, silencio, indicación formal, poesía

\begin{abstract}
Remarking on the importance of silence in Martin Heidegger's reflection on the question of being, this article proposes a possible interpretation of this motive in the unfolding of the existential analytic of Being and Time. Starting with a brief study of the comprehension of language expressed in this work, this essay considers the intimate bond between the becoming silent of being-there (Dasein) and the so called "propriety" (Eigentlichkeit) of its existence, which shows itself within the analysis of anxiety and the silent voice of conscience. The hermeneutical hypothesis raised will be related finally to the problem of formal indication and Heidegger's interpretation of poetical saying, mainly focused on Hölderlin's poetry, which began in the mid nineteen-thirties.
\end{abstract}

Key words: language, silence, formal indication, poetry

${ }^{*}$ Este trabajo fue realizado en la Albert-Ludwigs-Universität Freiburg gracias a la ayuda económica de una beca posdoctoral concedida por el Ministerio de Cultura, Educación y Ciencia. Agradezco al profesor Günter Figal su disponibilidad para comentar y discutir las ideas que aquí se exponen. 
Si no es una cuestión trivial que el surgimiento en Grecia de la pregunta por el ser tomara el lógos como hilo conductor para su dilucidación, tampoco puede serlo el que la recuperación por parte de Heidegger de esa pregunta se viera abocada, cada vez con mayor nitidez en el transcurso de los años, a una reflexión sobre el lenguaje. Sin embargo, es sabido que sólo el gesto de una ruptura permite en este caso articular tal aparente continuidad con la tradición. Del mismo modo que el replanteamiento heideggeriano de la cuestión ontológica se distancia polémicamente del conjunto de sus formulaciones precedentes en un intento de apuntar a lo nunca pensado en ellas, su atención por el lenguaje provocará la conmoción de todos aquellos momentos y presupuestos que configurarían su representación metafísica y que, en última instancia, podrían condensarse en su reducción a mero instrumento al servicio de la comunicación humana. Asumir la vinculación del ser al lógos pasará entonces por un enfrentamiento radical tanto con el significado tradicional de ambos términos, como con la relación establecida entre ellos desde los inicios de la filosofía.

En esa quiebra con la concepción metafísica del lenguaje ocupa un lugar destacado un motivo cuya relevancia sólo de manera parcial, y a mi juicio insuficiente, habría sido reconocida por la bibliografía específica sobre el tema: me refiero al asunto del silencio, del callar, que siempre acompaña a la reflexión de Heidegger sobre el decir. Es cierto que esta cuestión sólo en contadas ocasiones sería objeto de una tematización directa, y nunca de forma sistemática o exhaustiva. ${ }^{1}$ No obstante, la atenta lectura de sus textos confirma la notable recurrencia de ese motivo que, de modo errático pero continuo, atraviesa de un lado a otro la trayectoria heideggeriana, hasta el extremo de impedir la delimitación de algún tramo cronológica o metodológicamente significativo del que se hallara ausente por completo. Su presencia excede, por lo demás, el plano de la focalización expresa del fenómeno del lenguaje y se detecta allí donde, desde diversas perspectivas y con desigual grado de profundidad, el asunto del decir se ofrece a la mirada en sus diferentes concreciones: como discurso filosófico, decir poético, o habla en general. ${ }^{2}$ Pero más allá de su reiteración, la importancia de esta

\footnotetext{
${ }^{1}$ El más relevante de estos momentos sería quizá el que representa el conjunto de conferencias de los años cincuenta reunidas bajo el título Unterwegs zur Sprache.

${ }^{2}$ Por ello Wohlfahrt ha comentado: "Heidegger es el pensador del callar más relevante de la filosofía actual. Los pensamientos sobre el callar atraviesan casi la totalidad de su obra" (Wohlfahrt 1994, p. 71). Para justificar su afirmación, Wohlfahrt presenta un breve recorrido por algunas de las reflexiones de Heidegger sobre esta cuestión, correspondientes a diversos momentos de su trayectoria como
} 
cuestión reside en el sentido que Heidegger le confiere en el marco de su comprensión del lenguaje en particular y de su pensamiento en general. Aproximadamente a partir de mediados de la década de los treinta, el silencio o el callar comienzan a perfilarse en la obra heideggeriana como origen y fundamento del habla, de forma que, en consonancia con ello, la esencia del decir acabaría caracterizándose años más tarde como el son del silencio (Geläut der Stille) ${ }^{3}$. En torno a este problema aparecen además ciertas apelaciones a lo que se designa en términos de lo no-hablado (das Ungesprochene), lo no-dicho (das Ungesagte), o lo indecible (das Unsagbare), expresiones que presumiblemente señalarían a cierta dimensión sólo perceptible, de manera paradójica, en y a través del decir. ${ }^{4}$ A esto debe añadirse que tanto el silencio o callar como aquello que en el habla permanece no-dicho o callado quedarán íntimamente ligados, de forma más o menos explícita, a la cuestión del ser.

Este entrelazamiento con la cuestión ontológica sugiere que la tematización del silencio llevada a cabo por Heidegger bien pudiera inscribirse en el mismo movimiento de alejamiento de la metafísica que rige para su interrogación por el ser. Recordemos que tal movimiento estriba en el esfuerzo por sacar a la luz aquella diferencia cuya anulación, sepultamiento u olvido coincide con el propio acontecer de la metafísica, a saber, la diferencia entre el ser y el ente. El propósito de coherencia con respecto a esa toma de distancia frente a la tradición exigirá que la identificación heideggeriana del lógos con el espacio de comparecencia del ser se haga cargo de la problematicidad que entraña toda pretensión de decir tal ser. Pues si siempre se habla de y sobre serían, por ejemplo, los manuscritos de finales de los años treinta, donde comienza a plantearse el "pensar de la historia del ser" (seinsgeschichtliches Denken) o la confrontación con la poesía de Hölderlin (cfr. pp. 71-73).

${ }^{3}$ Así, cabe citar a modo de ejemplo el siguiente pasaje del curso de verano de 1937 titulado Nietzsches metaphysiche Grundstellung im abendländischen Denken: "El decir como callar (Erschweigen). Este decir también corresponde a la más profunda esencia del lenguaje, que tiene su origen en el callar (Schweigen)" (Heidegger 1986, p. 233). En la década de los cincuenta, esa misma esencia del lenguaje será determinada como el son del silencio, fórmula que vendría a expresar la diferencia entre mundo y cosa y que, según Heidegger, constituiría el fundamento del hablar humano: "el hablar del lenguaje como son del silencio de la diferencia (Unter-schied) hace acontecer el hablar mortal y su manifestación sonora" (Heidegger 2001, p. 31).

${ }^{4}$ Una de estas primeras apelaciones se localiza en el más temprano de los cursos que Heidegger dedica a la poesía de Hölderlin, impartido en el semestre de verano de 1934-1935. Esta problemática se abordará brevemente en el último apartado de este trabajo. 
aquello que "es", esto es, del ente, ¿̇cómo llevar al lenguaje lo que no es ente alguno sin convertirlo, en el instante en que deviene sujeto de enunciación, en una cosa sobre la que se habla? ¿Cómo decir el ser sin que esa misma operación del decir cancele su diferencia respecto del ente ${ }^{5}$ Por su propia especificidad frente a la metafísica, el proyecto heideggeriano desembocará en una reflexión sobre el lenguaje que necesariamente habrá de plantearse hasta qué punto y de qué manera cabe un hablar sobre el ser, o incluso en qué medida el decir, en lo relativo a esta cuestión, no podría tal vez estar topando con sus propios límites.

Si bien las referencias a lo no-dicho o lo no-decible mencionadas parecerían caminar precisamente en esta dirección, no resulta de entrada comprensible cómo su presencia en la obra de Heidegger puede convivir sin contradicción con la conocida determinación del lenguaje como la "casa del ser". ${ }^{6}$ La dificultad se agrava aún más ante el enigmático emplazamiento en el silencio del origen o fundamento del habla. Nos enfrentamos así a una particular ambivalencia en función de la cual el ser quedaría al mismo tiempo anclado al lenguaje y remitido al silencio; a la extrañeza de un decir el ser contradictoriamente traspasado por su propia negación, y de un callar sobre ese mismo ser sostenido y alojado dentro del habla. En esa bisagra entre el decir y lo no-decible, desde cuyo quicio cobraría sentido la afirmación heideggeriana de que "el ser es lo más dicho y al mismo tiempo el silenciamiento", 7 parece jugarse la posibilidad misma de la cuestión ontológica.

Una investigación en profundidad requeriría un seguimiento exhaustivo de este problema por la totalidad de la obra de Heidegger inviable dentro de los términos de este trabajo. Por ello, sin perder de vista el alcance global de la cuestión, mi objetivo será mucho más modesto y se

\footnotetext{
${ }^{5}$ Una reflexión explícita sobre esta dificultad puede encontrarse en el marco de los textos elaborados por Heidegger entre 1936 y 1938 editados bajo el título Beiträge zur Philosophie. Vom Ereignis, por ejemplo en el siguiente pasaje: "Con el lenguaje habitual, que hoy día es gastado y consumido de forma cada vez más extendida, no se deja decir la verdad del ser (Seyn). ¿Puede ésta ser dicha de manera inmediata, si todo lenguaje es, en efecto, lenguaje del ente? ¿O puede inventarse un nuevo lenguaje para el ser (Seyn)? No. Y si esto se consiguiera, incluso sin una formación artificial de palabras, este lenguaje no sería un lenguaje dicente" (Heidegger, 1994a, 78).

${ }^{6}$ Esta caracterización del lenguaje es introducida y explicada en el texto de 1946 "Brief über den Humanismus" (cfr. Heidegger 1976b, pp. 313-364, en concreto 333, 359 y 361), si bien años más tarde el propio Heidegger parecería desdecirse de ella al considerarla una expresión poco afortunada (cfr. Heidegger 2001, p. 90).

${ }^{7}$ Cfr. Heidegger 1981, p. 63.
} 
ceñirá al estudio de lo que, a mi juicio, debería constituir el punto de partida de tal indagación: la posición asignada al silencio en el marco de la analítica existenciaria elaborada en Ser y tiempo, cuyos momentos clave estarán significativamente marcados por el callar del ente que somos o ser-ahí (Dasein). En qué se cifra o qué representa ese callar, si se trata de un inevitable quedarse sin palabras frente a algo con respecto a lo cual la voluntad de decir se descubre como problemática, o si ese callar revela ciertos límites del habla y un supuesto terreno de lo no-decible, éstos son algunos de los interrogantes cuya respuesta se intentará ganar a través de la interpretación del sentido del silencio en el trazado de Ser y tiempo.

\section{Habla, lenguaje y silencio: el callar como modo de ser del habla}

Una primera objeción que cabría oponer a la idea de aproximarse a la temática del silencio en el pensamiento de Heidegger desde su obra temprana es la que apuntaría a la aparente distancia, e incluso conflicto existente, entre la concepción del lenguaje planteada en la obra de 1927 y la que desarrollaría años más tarde, distancia que condicionaría el significado de la reflexión sobre el silencio en uno $\mathrm{u}$ otro momento de su trayectoria. Así como en escritos más tardíos el lenguaje emerge con nitidez como la instancia posibilitante de la abertura al ser que acontece en el hombre, su papel en la arquitectura de Ser y tiempo es poco claro y, tanto del escaso espacio dedicado a su dilucidación como de su ubicación en el orden expositivo del texto, semejaría derivarse su subordinación al resto de elementos integrantes de dicha abertura. ${ }^{8}$ Sin embargo, ambos factores se verán desbordados por las caracterizaciones efectuadas sobre el fenómeno que Heidegger nombra en esta obra con la noción de "habla" o "discurso" (Rede) en tanto fundamento

\footnotetext{
${ }^{8}$ Como ha señalado Sallis, la diferencia entre Ser y tiempo y momentos posteriores del pensamiento heideggeriano como el que representaría, por ejemplo, la "Carta sobre el humanismo", estriba en que en 1927 el lenguaje se presenta de entrada como un mero derivado del tercero de los componentes del "ahí" constitutivo del ser del ente que somos, esto es, del habla, mientras que en aquélla ese mismo lenguaje es "precisamente el constituyente del ahí. Sólo el lenguaje, por lo que parece, es ahora contemplado como lo que capacita al ser-ahí para ser su ahí" (Sallis 1970, p. 384). No obstante, desde una perspectiva acorde con la que aquí se propondrá, Sallis mostrará que afirmaciones como esta última únicamente supondrían una suerte de apropiación de lo ya dicho sobre el lenguaje en Ser y tiempo, y en ningún caso una alteración significativa de la función que allí se le atribuye en la abertura al ser del ser-ahí.
} 
ontológico-existenciario del lenguaje. ${ }^{9}$ En ellas me detendré a continuación, puesto que un modo destacado de esa habla será precisamente el callar o el silencio.

En Ser y tiempo, la constitución ontológica del ser-ahí como lugar de comparecencia de todo aquello que es depende de los dos modos fundamentales de su ser, complejamente engarzados entre sí, que representan el "encontrarse" (Befindlichkeit) y el "comprender" (Verstehen). Junto a ellos, el habla se introduce como un tercer momento esencial en la configuración de ese espacio o "ahí" tan originario como aquellos, pero de estatuto claramente distinto: lejos de tratarse de otro modo de ser situado en un plano de horizontalidad con respecto a los anteriores, Heidegger advierte que tanto el encontrarse como el comprender se hallarían "cooriginariamente determinados por el habla", ${ }^{10}$ esto es, ya de antemano atravesados o vertebrados por el hablar. ${ }^{11}$ Ello explica que al inicio del análisis de este existenciario se comente que la previa descripción de tales dos modos de ser ya habría hecho uso de él de manera constante aun sin focalizarlo propiamente (Heidegger 1993, pp. 160 y s.). La indicación de que la dilucidación del fenómeno del habla rebasaría aquellos parágrafos en los que es objeto de una tematización expresa vendría a corroborar lo que ya la relación establecida entre los tres elementos integrantes de la abertura al ser del ser-ahí parece evidenciar en este punto, a saber, que la determinación ejercida por el habla sobre el encontrarse y el entender implica el carácter esencialmente lingüístico de esa abertura y, por tanto, la imposibilidad de pensarla como algo ajeno al hablar humano. ${ }^{12}$ Esta lectura se mostraría, por otra parte, perfectamente coherente con la perspectiva adoptada en las lecciones impartidas en los años previos a la publicación de Ser y tiempo, donde el concepto griego del lógos, también asimilado en 1927 al habla (Heidegger 1993, p. 32), será interpretado como el fundamento de su vinculación al mundo. ${ }^{13}$ Pero su validez en el marco de Ser y tiempo sólo podrá ratificarse una vez que se perfile, al menos en sus rasgos

${ }^{9}$ Cfr. Heidegger 1993, p. 160.

${ }^{10}$ Ibid., p. 133. Las cursivas son mías.

${ }^{11}$ De ahí que von Herrmann afirme que el existenciario del habla tendría incluso una esencia más alta que el comprender y el encontrarse "porque interviene en y recorre todos los demás existenciarios" (von Herrmann 1985, p. 113).

${ }^{12}$ Desde diferentes puntos de vista y apelando a argumentos de diversa índole, esta interpretación ha sido defendida por autores como: Sallis (1970, pp. 381-397); von Herrmann (1985, pp. 92-198); Jaeger (1971, pp. 5-21), o Stenstad (1988, pp. 16-20), entre otros.

${ }^{13}$ Así, por ejemplo, en la lección del semestre de verano de 1924, dedicada al análisis de conceptos fundamentales de la filosofía aristotélica, se dirá al respecto: 
principales, qué es eso que Heidegger llama habla y cuál es su relación con lo que habitualmente entendemos por lenguaje.

En el parágrafo 34 el habla se define como la "articulación de la comprensibilidad (Verständlichkeit) del ahí" o, según otra formulación, como la "articulación 'significativa' de la comprensibilidad, ligada al encontrarse, del ser-en-el-mundo" (Heidegger, 1993, p. 161). La manifestación del ente en general que tiene lugar en el ser-ahí a través del comprender y el encontrarse aparece ahora sometida a una cierta articulación, que se correspondería con la llevada a cabo por el habla. Si el hablar supone, además, un articular "significativo", es porque, añade Heidegger, lo articulado por él se identifica con una "totalidad de significado" (Bedeutungsganze) susceptible de ser descompuesta en significados particulares. Por otro lado, a tal totalidad significativa le es inherente el haber llegado siempre ya a la palabra, es decir, el haberse instalado de antemano en una realidad material que la dota de un ser intramundano. Esta dimensión óntica del habla, siempre operante de manera tácita o explícita, es la que se plasmaría en el concepto de lenguaje, concepto que semejaría quedar incluido dentro de la noción más amplia del habla al modo de una faceta o aspecto suyo, si bien necesario e inalienable, no abarcante de su pleno sentido. ${ }^{14}$ A diferencia del lenguaje, el habla remitiría a una articulación significativa que se hallaría a la base de la articulación sonora característica de aquél.

La idea de una articulación subyacente a y de naturaleza diversa frente a tal articulación puramente sonora no resulta en absoluto ajena a la comprensión tradicional del lenguaje. Antes bien, Heidegger sostendrá en Ser y tiempo que dicha comprensión se habría forjado tomando como hilo conductor la estructura de la proposición o enunciado,

"[El lógos] es la determinación fundamental del ser del hombre en cuanto tal. [...] El ser-en-el-mundo del hombre está determinado en su fundamento por el hablar. El modo fundamental de ser del hombre en el mundo es hablar con él, sobre él, de él. Precisamente de esta manera está el hombre determinado por el lógos" (Heidegger 2002, p. 18).

${ }^{14}$ Así, se señala en ese mismo parágrafo 34: "Si el habla, la articulación de la comprensibilidad del ahí, es un existenciario original del estado-de-abierto, pero éste resulta constituido primariamente por el ser-en-el-mundo, también el habla tendrá esencialmente una específica forma de ser mundana. La comprensibilidad, mediada por el encontrarse, del ser-en-el-mundo, se expresa como habla. [...] La exteriorización expresiva del habla es el lenguaje. Esa totalidad de palabras en la que el habla tiene un peculiar ser 'mundano' puede así, como ente intramundano, ser encontrada delante como algo a la mano" (ibid., p. 161). Reforzando esta misma idea se afirma un poco más adelante: "Ordinariamente el habla se expresa y se ha expresado siempre ya en palabras. El habla es lenguaje” (ibid., p. 167). 
consistente en la articulación entre un sujeto y un predicado que lo determina expresamente. La forma " $S$ es $P$ " del enunciado simple equivale a la presentación de "algo como algo", a la manifestación de un sujeto a la luz del rasgo o propiedad destacado por el predicado, y es en ese enlace entre uno y otro donde se produce el decir enunciativo. Su estructura recibe la denominación de "como apofántico" (apophantisches Als), pues el "algo como algo" de la proposición involucra la mostración explícita del sujeto desde la determinación predicativa. Por ello, la expresión más tangible de esta articulación tendrá lugar en el terreno de la aproximación cognoscente a la realidad, esto es, en el juicio puramente teórico. Sin embargo, Heidegger difícilmente podría referirse a esta articulación al exponer el fenómeno del habla: mientras ésta se inscribe en el conjunto de estructuras fundamentales por las que el ser-ahí se revela lugar de comparecencia de todas las cosas, Ser y tiempo defenderá la tesis del carácter no originario o derivado tanto del enunciado como del tipo de presentación que en él se genera. Cualquier aserción enunciativa presupone necesariamente el ser ya manifiesto de aquello sobre lo cual se enuncia algo, patencia que sería el resultado de una articulación previa al "como apofántico" pero por lo general inexpresa y, según Heidegger, velada por esa misma estructura proposicional. Intentemos aclarar en qué consistiría dicha articulación.

Esa patencia de las cosas, siempre anterior al juicio, acontece en el simple y cotidiano habitar el mundo del ser-ahí, en su constante habérselas de un modo u otro con todo aquello que le rodea. En él cada cosa se da a ver por vez primera como aquello que es desde su "serpara" (Um-zu) una posibilidad o conjunto de posibilidades de su trato o manejo, es decir, para aquello que el ser-ahí puede hacer con ella. Así, la tiza que está junto al encerado se descubre primariamente como tal en función del poder escribir con ella, desde el "para-escribir" en cuanto posibilidad entre otras del ser-ahí, del mismo modo que la lámpara se muestra como lámpara desde el iluminar para el cual sirve o la puerta como puerta para entrar y salir por ella. En tales posibilidades o modos de ser concretos habita de continuo el ser-ahí de manera por completo atemática, pues, como asevera Heidegger, "vivo en la comprensión del escribir, iluminar, entrar y salir [...]. Mi ser-en-el-mundo no es otra cosa que este moverse siempre ya comprensivo en estos modos de ser" (Heidegger, 1976a, p. 146). Sin embargo, el para-qué que permite el manifestarse de las cosas no sucede en ningún caso de modo aislado, sino integrado en una cadena de "paras", de referencias, también implícitamente comprendida, que sólo se detiene en la propia existencia del ser-ahí, en el proyecto que representa su ser. Siguiendo con el ejemplo, 
el escribir con la tiza remite a otros posibles "para", como podría ser explicar un problema matemático, que a su vez podría remitir, entre otras posibilidades, a la profesión docente, la cual quedaría por su parte referida a la necesidad de procurarse un sustento que, en última instancia, apuntaría al proyecto de ser del cual el ser-ahí siempre ya se ha hecho cargo de una forma u otra. Tal cadena de "paras" engarza asimismo con otra serie de referencias de índole variada: el material del cual está hecha la tiza, que debe ser de yeso y no, pongamos por caso, de algodón, si debe servir para escribir; el resto de útiles que la acompañan, como la pizarra o el borrador, a su vez exhibidos en el contexto de un aula cuyo mobiliario remite a sus ocupantes, los alumnos y profesores, a la institución universitaria...

La totalidad formada por esta compleja red o tejido referencial configura el trasfondo sobre o a partir del cual cada cosa comparece como aquello que es. En cuanto condición de posibilidad de la aparición de cada cosa concreta, ese trasfondo se halla siempre ya de antemano descubierto y comprendido por el ser-ahí de forma atemática, si bien, como habrá ocasión de comprobar, determinadas situaciones harán recaer la atención sobre él. ${ }^{15}$ En dicho entramado de remisiones de carácter global se localizará el fenómeno del mundo. En este contexto, Heidegger apelará a esa estructura referencial por la cual el desvelamiento de cada cosa es solidario del habérselas del ser-ahí con ella en términos de un "significar" (be-deuten) (Heidegger, 1993, p. 87), de tal suerte que de algo se dirá que está dotado de significado precisamente en cuanto es comprendido en función de su para-qué y del trasfondo remisional que lo acompaña. De ahí que la estructura del mundo en tanto totalidad referencial se designe con la noción de significatividad (Bedeutsamkeit).

A partir de esta breve presentación del fenómeno del mundo cabe ahora señalar que la articulación previa al enunciar vigente en el cotidiano aparecer de las cosas no es sino aquélla por la cual la manifestación de cada cosa se produce siempre desde algo otro, esto es, desde el para-qué de su utilidad y la trama referencial en la que éste se inserta. El salir de algo al encuentro del ser-ahí acaece así únicamente en función de su tácita articulación con determinada posibilidad de ser de éste - el escribir, el iluminar, el entrar y salir...- , a su vez significativa por su pertenencia a un tejido remisional. Por ello, comentará Heidegger, esa articulación es ya susceptible de concebirse como una síntesis o composición entre aquello a partir de lo cual algo se descubre y la

${ }^{15}$ Una de ellas, como se verá más adelante, será la del acaecimiento del estado de ánimo de la angustia, en la que ese trasfondo se pondrá de relieve a causa de su transitoria pérdida de sentido. 
cosa descubierta, síntesis que al mismo tiempo implicaría una diáiresis o separación de ambos momentos. Sobre la base de la unidad originaria de tales síntesis y diáiresis descansaría la composición tradicionalmente atribuida al enunciado. ${ }^{16}$ Frente al "como apofántico" característico de éste, la estructura de esta articulación primaria y no expresa recibirá el nombre de "como hermenéutico" (hermeneutisches-Als) por constituir el fundamento de toda interpretación comprensiva. De ella derivará el "como apofántico" de la predicación: en ésta la cosa en cuestión se verá desgajada del contexto significativo posibilitante de su aparición primaria para determinarse, no ya en función del para-qué inherente a dicha aparición, sino a partir de las propiedades accesibles en su mera contemplación. Al orientarse hacia lo meramente presente en la cosa, la predicación entrañará el encubrimiento de su modo originario de ser y de la articulación hermenéutica sobre la que reposa. Pero esta cuestión habrá de ser analizada más adelante con mayor detalle.

El hecho de que la articulación hermenéutica vertebre de manera constitutiva todo comprender ${ }^{17}$ sugiere su identificación con la asignada al habla, definida, según se dijo, como la articulación significativa de la comprensibilidad del ahí. El concepto de habla vendría entonces a apuntar a la estructura referencial o significativa presente en toda relación del ser-ahí con las cosas que le rodean, tanto si ésta ocurre efectivamente ligada a la emisión de palabras como en su ausencia. Ello no quiere decir, sin embargo, que cupiera aislar el fenómeno del habla de su materialización sonora en el lenguaje. Ya se indicó la intrínseca vinculación de la totalidad de significados articulada por el habla a la palabra, totalidad que, en función de lo expuesto, puede ahora asimilarse a la significatividad. ${ }^{18}$ Pese a la parquedad con que

${ }^{16}$ Cfr. Heidegger 1976a, pp. 148 y s.

${ }^{17}$ Aun cuando de la lectura de Ser y tiempo no se infiere con suficiente claridad ese carácter ya en sí mismo articulado o hermenéutico del comprender, es decir, el que este existenciario básico se encuentre ya constitutivamente articulado por medio de la estructura del "como hermenéutico", otros textos de la misma etapa lo confirman de manera indiscutible. Así, por ejemplo, el citado curso del semestre de verano de 1925-1926 señalará con respecto a ese "como" que se trata de "la estructura que pertenece al comprender en cuanto tal" (Heidegger 1976a, p. 150, n. 6). También en el curso posterior a Ser y tiempo impartido entre 1929 y 1930 , Heidegger atribuirá a la noción de proyecto la estructura de una síntesis y diáiresis originarias y defenderá la dependencia de toda mostración de algo en general del "como hermenéutico" que lo articula, afirmando asimismo que "solamente se nos da algo si ya nos movemos en el proyecto, en el 'como'" (Heidegger 1983, pp. 530 y s.).

${ }^{18}$ Esta identificación de la totalidad de significados articulada por el habla con la significatividad ontológicamente constitutiva del mundo vendría también avalada 
la obra de 1927 tematiza esta cuestión, las explicaciones al respecto invitan además a postular la imposibilidad de tal tejido remisional sin la existencia del lenguaje, por más que tal entramado no coincida del todo con éste. Pues es precisamente en esa materialización del habla donde se encierra aquella comprensión previa del mundo y del ser-ahí por la que éste se rige cotidianamente en su particular proyecto de ser. Según leemos en Ser y tiempo: "La expresión lingüística alberga, en el todo articulado de sus conexiones de significación, una comprensión del mundo abierto" (Heidegger 1993, p. 168). ${ }^{19}$ Con ello quedaría confirmado el carácter inmanentemente lingüístico de la abertura al ser del ente que somos. No obstante, la introducción del concepto de habla en su diferencia frente al lenguaje pondría de relieve cómo toda presencia requiere de una estructura referencial, es decir, de un significar o remitir a algo desde algo otro, en esencia indisociable del sistema material de signos que aquél supone pero no reductible a él: la noción de habla excede a la de lenguaje desde el momento en que alude al anclaje de ese decir sonoro en el atemático andar con las cosas en que acontece, a su raigambre en las diversas prácticas o conductas en las que tal andar cobra concreción. ${ }^{20}$ Desde esta perspectiva, en la articulación denotada por el habla se entrelazarían la dimensión puramente lingüística del

por el curso del semestre de verano de 1925, donde en el contexto de un análisis del fenómeno del mundo ya muy similar al de Ser y tiempo se afirma: "Las remisiones y contextos de remisiones son primariamente significado. Los significados son —según lo dicho anteriormente- la estructura de ser del mundo. El todo de remisiones del mundo es un todo de conexiones de significado, significatividad" (Heidegger 1979, pp. 286 y s.). En él se señalará de manera expresa, por otra parte, tanto la conexión semántica del término "significatividad" con la acepción puramente lingüística del concepto de significado —en cuanto significado de una palabra-, como la íntima relación existente entre el fenómeno del mundo y el del habla (ibid., p. 275).

${ }^{19}$ En cuanto a la íntima vinculación entre significatividad y lenguaje ha señalado Kockelmans: "Esta totalidad de sentido nos viene dada en gran parte en el lenguaje que hablamos, dado que nuestra familiaridad con nuestra cultura nos llega mayoritariamente a través de lo que escuchamos o leemos. Por tanto, y especialmente en este lenguaje, nuestro mundo se nos aparece como la totalidad ya presente de toda posible referencia, totalidad dentro de la cual cada cosa concreta puede aparecer como esto o aquello. De ahí que el hombre y las cosas sólo puedan conectarse significativamente dentro del mundo que se dirige a nosotros en y a través del lenguaje" (Kockelmans 1972, p. 29). Disiento además en este punto de Hübner, quien en lo relativo a esta cuestión pretende que Heidegger habría sostenido la independencia del plano significativo respecto del lenguaje (cfr. Hübner 2001, pp. 102-108).

${ }^{20}$ En este sentido, Aler ha indicado que el análisis heideggeriano "no se ocupa del lenguaje como la serie de posibilidades sistematizadas de expresión por medio de símbolos que aparece en sus posibles combinaciones de sonidos vocales; más 
decir y el moverse significativo por el mundo sobre el que tal decir se fundamenta y tiene lugar. Heidegger negará por ello que el análisis del enunciado pueda dar cuenta del fenómeno del habla, pues la estructura apofántica resulta precisamente de la suspensión y ocultación circunstancial de ese entrelazamiento. Por otra parte, semejante lectura justifica que el callar o guardar silencio se considere en esta etapa como un modo de ser del habla, es decir, como un modo de ser por medio del cual, sin pronunciar palabra alguna, el ser-ahí significa o da a entender algo.

Lejos de tratarse de una modalidad entre otras, el callar se revelará como una "posibilidad esencial del habla" (Heidegger, 1993, p. 165) de incuestionable valor en el desarrollo de la analítica existenciaria. Tanto, que la llamada "propiedad" (Eigentlichkeit) del ser-ahí, de la cual dependerá en última instancia la dilucidación del sentido de su ser como objetivo clave de la investigación ontológica de Ser y tiempo, se cifrará en un movimiento de apropiación de sí ligado al silencio: en el origen de ese movimiento Heidegger situará la llamada de una conciencia que, frente a sus exégesis tradicionales, carecerá de voz alguna y será capaz de acallar toda otra voz. Veámoslo con más detenimiento.

\section{La vocación de la conciencia: silencio y propiedad}

\subsection{Angustia e insignificatividad}

El tejido remisional que conforma el fenómeno del mundo y patente en el lenguaje presupone la pertenencia del ser-ahí a una comunidad de semejantes, a un medio social en el que tal red de significados se instaura a partir del conjunto de prácticas, creencias o formas de vida compartidas por sus miembros. Cada ser-ahí accede de entrada a las cosas que le rodean desde un trasfondo común que de antemano habría fijado cuáles son los modos de conducirse frente a ellas o las posibilidades de la existencia. Sin embargo, es sabido que una de las ideas centrales de Ser y tiempo radica en el ser "en cada caso mía" (Jemeinigkeit) de esa existencia: en tanto arrojado a un ser consistente en poder-ser, es decir, en un proyecto o constante estar en camino hacia posibilidades de sí, el ser-ahí debe en cada caso decidir desde sí mismo el curso de su propio devenir proyectándose en una otra posibilidad de su ser (Heidegger 1993, p. 42). En el contraste y tensión entre esa abertura pública y compartida al ente, por un lado, y la irreductible singularidad con la que cada ser-ahí se halla entregado a su propio ser,

bien trata del discurso como aquella forma de la conducta humana en la que estas posibilidades llegan a materializarse" (Aler 1972, p. 46).

Diánoia, vol. LIII, no. 61 (noviembre 2008). 
por otro, cabe ubicar la polaridad establecida en esta etapa entre los conceptos de propiedad e impropiedad: el ser-ahí es cotidianamente impropio (uneigentlich) porque tal abertura a través de una significatividad común, al tiempo que permite su trato con las cosas, tiende a desdibujar, a encubrir esa singularidad, sometiéndola a una particular indiferenciación. En lugar de ser "él mismo", el ser-ahí se aparece en su cotidianidad como uno cualquiera, uno de tantos, reemplazable en la posición que ocupa. Su modo de ser habitual se asimila al del sujeto impersonal que Heidegger denominará el "se" o el "uno" (das Man). En él se "articula el plexo de referencias de la significatividad" (Heidegger 1993, p. 129), el universo de discurso que determina cómo "se" trabaja, cómo "se" actúa y, en general, cómo "se" vive, cuya voz anónima adopta regularmente el ser-ahí.

Debe advertirse que ni la impropiedad ni la figura del uno se dejan interpretar como modos de ser susceptibles de modificación o abandono. Antes bien, se trata de estructuras ontológicas constitutivas del ser-ahí, insustituibles en su descubrimiento cotidiano del ente en general. La ambivalencia, también constitutiva, que ello generará en tal descubrimiento se refleja de manera eminente en el lenguaje. Por poseer siempre ya una realidad material y configurar el dominio de fijación de la significatividad, el habla envuelve un componente de desfiguración y encubrimiento inseparable de su potencia desveladora que en Ser y tiempo se expresará por medio de la noción de las habladurías (Gerede): la mera repetición y consolidación del universo público de discurso hace pasar automáticamente por verdadera la comprensión de las cosas que vehicula, de suerte que lo ya dicho y difundido de manera pública se erige en principio de autoridad, tornando hasta cierto punto prescindible el conocimiento directo de aquello sobre lo cual se habla. Puesto que, más que acercar a lo que las cosas sean, lo hablado acaba provocando un alejamiento de ellas, en el fenómeno de las habladurías el lenguaje se muestra condición de abertura en la misma medida que de ocultación, esto es, fuente simultánea de verdad y falsedad. Este fenómeno integrará asimismo lo que Heidegger denomina la caída o "estado-de-caído" (Verfallenheit) del ser-ahí. Pese a sus resonancias claramente negativas, también este concepto define un rasgo fundamental e inalienable en su configuración ontológica: el que el ser-ahí se encuentre, según se afirma en Ser y tiempo, siempre ya inmediatamente caído en el mundo, remite a su estructural "ser-cabe" (Sein-bei) el ente intramundano, es decir, a la necesaria vinculación de su propio proyecto de ser a los demás entes que ante él se manifiestan, cotidianamente acontecida a través de la forma de ser del uno. Como acabamos de 
observar al hilo del análisis de este último existenciario y de las "habladurías", dicha vinculación comportará de manera indefectible una serie de encubrimientos cuyo verdadero alcance aún debemos especificar. ${ }^{21}$

La ambivalencia característica de la cotidianidad del ser-ahí se verá quebrada por la irrupción repentina de la llamada de la conciencia, instancia que en Ser y tiempo se sustraerá a su tradicional interpretación ética para adquirir un valor estrictamente ontológico. La llamada de la conciencia no adopta la forma de una fonación sonora: no hay en ella voz alguna que dicte órdenes ni, en consecuencia, posibilidad de escuchar sus mandatos; por el contrario, la conciencia habla sólo en la modalidad del callar. Pero la ausencia de palabras no implica que lo dado a entender en ella sea algo oscuro e impreciso. Frente al bullicio y equivocidad del lenguaje cotidiano, dominado por las habladurías y la publicidad, la conciencia habla en su callar de manera inequívoca. Su función estriba en silenciar toda voz, tanto las voces ajenas como la de aquel que recibe la llamada, ya de antemano conquistada por ellas y por eso asimilada a la voz pública del uno. En la medida en que la vocación fuerza al ser-ahí a callar, a guardar silencio sobre sí mismo, éste, dice Heidegger, "permanece indeterminado y vacío en su "qué". La manera como el ser-ahí interpreta inmediata y regularmente lo que él es desde aquello que le ocupa es dejada de lado por la llamada" (Heidegger 1993, p. 274). Ante la voz silenciosa de la conciencia, el ser-ahí se ve impelido a abandonar el modo de ser del "uno" que cotidianamente le habita y desde el cual se comprende en función de su actividad en el mundo. De ahí que la vocación de la conciencia suspenda todo hablar sobre sí, todo decir acerca de lo que se es o se deja de ser, en cuanto autointerpretación como tal o cual cosa siempre procedente de la significatividad del mundo.

Pero, ¿qué es lo que permite que la conciencia logre tal acallamiento de la voz anónima del uno que habla en el ser-ahí? ¿Por qué razón esa llamada se identifica con una llamada silenciosa capaz de acallar cualquier otra voz? Para responder a estas cuestiones es preciso retrotraerse al origen de la vocación de la conciencia, origen a partir del cual cabrá a su vez explicar por qué se trata de un silencio inequívoco y, por tanto, relevante, frente a otras situaciones en las que el callar del ser-ahí pudiera revelarse un asunto trivial. Pese a la extrañeza con que sobreviene, Heidegger advierte que la llamada de la conciencia no

${ }^{21}$ Para un estudio más detallado de la problemática que conlleva la interpretación de los conceptos de propiedad e impropiedad en Ser y tiempo, así como el sentido del concepto de caída en la acepción que aquí presentamos, nos permitimos remitir a nuestro artículo: Martínez Matías 2005, pp. 395-420.

Diánoia, vol. LIII, no. 61 (noviembre 2008). 
emerge sino del propio ser-ahí. Pero éste no la reconoce como propia porque tal vocación irrumpe desde un específico estado de ánimo que trae consigo la experiencia de un extremo desarraigo del que el ser-ahí, de continuo, pretende no saber. Este estado de ánimo es la angustia, cuyo acaecimiento, como se constatará de inmediato, habrá de dejar al ser-ahí sin habla. En una suerte de desdoblamiento de sí, el ser-ahí sumido en la angustia se invocará a sí mismo a salir de su cotidiano estado de pérdida en el modo de ser del uno.

En el contexto del análisis de este estado de ánimo, Heidegger destaca que el movimiento de huida de sí trazado por el ser-ahí en su caída presupone la patencia de aquello ante lo cual se pone en fuga, si bien esa patencia se daría justamente a través de su constante evitación. Semejante huida de sí no es otra que la que representa su dedicación a las cosas manifiestas en el mundo. Frente a ella, la angustia se describe como aquel temple anímico en que lo eludido por la caída se impone de pronto al ser-ahí al cerrársele la posibilidad de entregarse al ente en general. Por otro lado, este estado de ánimo no se deja confundir con el temor: así como éste vendría provocado por el carácter amenazante de algún ente en concreto, la vinculación a todos ellos queda cortada de raíz en la angustia. En ella se produce un estado de detención, de quiebra de todo posible habérselas del ser-ahí con aquello que habitualmente le mueve. De repente, sin previo aviso, todo lo que aparece ante él se ha vuelto irrelevante, carente de importancia. El serahí se ve así sumido en la máxima impotencia: las cosas siguen estando ahí, permanecen en su lugar de costumbre y aparentemente nada ha desaparecido ni cambiado; sólo la posibilidad de tratar con ellas. Esa indiferencia que de manera inusitada colorea la totalidad del ente y fuerza a la parálisis indica su sorpresiva falta de significatividad, es decir, su insignificatividad (Unbedeutsamkeit). La totalidad referencial subyacente a la mostración de cada cosa se ha hundido en el estado de ánimo de la angustia, tornándose en su contrario: el mundo en su conjunto queda momentáneamente reducido a "nada". Pero si el serahí sobrecogido por la angustia siente la "nada" del mundo como una amenaza es porque, de modo paradójico, el mundo se ha vuelto patente a causa de su quiebra o hundimiento. Mientras el trato cotidiano con el ente acontece sobre la base de una comprensión atemática del plexo referencial posibilitante de su aparición, y por tanto, de su carácter no manifiesto, la angustia lo hace aflorar por su falta de disponibilidad: el entramado constitutivo del mundo comparece justo en su perderse, queda iluminado, atenazando al ser-ahí, en su pura insignificatividad. Por ello, Heidegger declarará que "el angustiarse abre originaria y di- 
rectamente el mundo como mundo" (Heidegger 1993, p. 187), es decir, en su divergencia con respecto al ente intramundano y desde la plena articulación del ser-en-el-mundo en que consiste el ser-ahí.

La llamada silenciosa de la conciencia brotará así del ser-ahí dominado por la angustia, forzado a callar bajo el influjo de este estado de ánimo. Sólo tras su acaecimiento podrá decir, acertando en sus palabras, que lo que le sucedía en realidad no era "nada". Como se formulará poco después en la conferencia de 1928 "¿Qué es metafísica?": "La angustia nos deja sin palabra. Puesto que lo ente en su totalidad se escapa y precisamente ésta es la manera en que nos acosa la nada, en su presencia enmudece toda pretensión de decir que algo 'es'. Que sumidos en medio de la extrañeza de la angustia tratemos a menudo de romper esa calma vacía mediante una charla insustancial no hace sino demostrar la presencia de la nada". Heidegger no dice que el serahí angustiado no pueda hablar. Más bien ocurre que toda intención de decir algo deviene vana, irrelevante, ante la propia irrelevancia que ha prendido a la totalidad del ente. Y puesto que hablar significa siempre hablar de cosas, de entes, es decir, de aquello que, como la cita recalca, "es", no cabe decir relevante cuando toda cosa ha caído en la irrelevancia. La charla insustancial mencionada por Heidegger no supondría en el fondo más que una prueba de esa irrelevancia del decir: al igual que el hundimiento de la significatividad torna inviable el manejo cotidiano del ente, tampoco es posible en la angustia el hablar que ese manejo involucra. La única modalidad del habla operante en este estado de ánimo será el callar.

Pero el análisis de la angustia no puede detenerse en este punto si se desea alcanzar el pleno sentido de ese callar del ser-ahí a su vez referido al silencio de la llamada de la conciencia. En la medida en que el mundo constituye uno de los elementos analíticamente diferenciables del seren-el-mundo que articula al propio ser-ahí, su manifestación en cuanto "nada", su hacerse patente en el modo de su pérdida, sólo plasmará un aspecto parcial del desvelamiento de su ser generado por este estado de ánimo frente a su encubrimiento cotidiano. Trasladado al marco de reflexión de la conciencia, lo desvelado por la angustia coincidirá con aquello que ésta da a entender en el silencio de su vocación. Y es aquí, como se verá a continuación, donde habrá de plantearse la cuestión acerca de si lo vehiculado por ese silencio se dejaría igualmente decir a través de la palabra o si, por el contrario, dicho silencio no obedecería más bien a cierta dificultad o incluso imposibilidad de expresarlo por medio de ella. 
2.2. Inhospitalidad y muerte: los límites del decir

El efecto de la experiencia de la "nada" procurada por la angustia no se restringe a la inhabilitación del ser-ahí para comprometerse de un modo u otro con todo aquello que le rodea. Si recordamos, la articulación de la significatividad del mundo descansa sobre la figura del uno, de manera que la inesperada quiebra de tal entramado significativo lanza al ser-ahí fuera de esa posición en la que habitualmente se ha instalado y le impide refugiarse en su anonimato: paralizado por la angustia, el ser-ahí se verá súbitamente aislado, remitido a sí mismo y a su irreductible singularidad como único asidero factible. Privado de su cotidiana dispersión en la impersonalidad de ese sujeto que no se distingue como nadie en concreto, ya no podrá rehuir el "ser en cada caso mía" de su propia existencia. Paradójicamente, es en este estado de máxima impotencia cuando el ser-ahí descubre en su ser un ser-posible del cual sólo él y nadie más puede hacerse cargo, una posibilidad siempre abierta que le atañe de manera exclusiva y absoluta.

En relación con ello, Heidegger afirma que la radical singularización impuesta por la nada del mundo trae a la luz aquello que la caída se esfuerza constantemente por ocultar: el carácter esencialmente inhóspito de su ser, su originario no-ser-en-casa. Como leemos en Ser y tiempo: "La fuga cadente hacia el en-casa de la publicidad es fuga ante el noen-casa, es decir, ante la inhospitalidad que reside en el ser-ahí como ser-en-el-mundo arrojado y entregado a sí mismo en su ser" (Heidegger 1993, p. 189). Al expulsarlo del ámbito familiar del mundo que por lo general lo ampara, la angustia enfrenta al ser ahí con su hallarse de antemano arrojado a un ser que, en cuanto pura posibilidad, representa para él una tarea nunca agotada, cuyo peso debe por fuerza asumir. Por otra parte, tanto la insignificatividad del ente en total como su reducción a ese desnudo poder-ser obligarán al ser-ahí a reconocerse como la "nada" que en realidad es, es decir, como "nada" más que el lugar para la comparecencia de todas las cosas: ser-en-el-mundo equivale a no ser cosa alguna, sino sólo la abertura donde la totalidad del ente se da a ver. No obstante, el paulatino despliegue de la analítica existenciaria pondrá de manifiesto que tanto el fenómeno de la angustia como la inhospitalidad y la nada que en ella afloran tendrán su verdadera raíz en un rasgo ontológico aún no mencionado, pero tan esencial en el ser-ahí que a él se subordinará la completa inteligibilidad de tales conceptos.

El ser-ahí no sólo se encuentra arrojado a ser en ausencia de toda decisión por su parte. Ese ser del cual debe erigirse en fundamento sin tan siquiera poder dar razón de él lleva constitutivamente inscrito el 
signo de la muerte, de la finitud. Ello quiere decir que, lejos de concebirla como un suceso existencial que pone fin a la existencia del ser-ahí, Heidegger interpreta la muerte como un modo de su ser inalienable a su configuración ontológica. En la medida en que toda referencia a sus posibilidades de ser encierra de antemano la concerniente a su posible no-ser, el ser-ahí se define como un "ser relativamente a la muerte" (Sein zum Tode). Es más, ésta lo atraviesa de lado a lado hasta el punto de que cada uno de sus actos reposará tácitamente sobre su haber-demorir, pues la huida de sí inducida por la caída evidencia en última instancia un constante rechazo de la muerte: en su cotidiana asimilación al uno, el ser-ahí esquiva con tenacidad el hecho de que, al igual que su ser, también su dejar de ser, terreno absolutamente ajeno a toda representatividad o intercambio, le incumbe de manera irreductible. En consonancia con ello, la identificación de la muerte ya no con su punto de cierre, sino con un fenómeno de la existencia, sugiere que toda angustia vendría en el fondo motivada por ese inevitable no-ser. En primer lugar, porque precisamente de su perspectiva depende la transformación repentina de la significatividad del mundo, sujeta en última instancia al por-mor-de-sí de este ente, en su contrario: la nada del mundo patente en este estado de ánimo refleja la de su posible y a la vez segura desaparición, ante la cual todo ese entramado significativo carece de sentido. Por otro lado, el que en la angustia su ser llegue a trasparecer como el poder-ser que ya siempre es se sigue de la anticipación de su muerte: sólo el no absoluto de la imposibilidad de la existencia, imposibilidad que se traduce a su vez en la única posibilidad siempre incumplida e irrealizable frente a él, le volverá capaz de comprenderse como el ser-posible que es en cada caso. ${ }^{22}$ De todo ello se deduce que ese momento de quiebra de lo cotidiano supone el alumbramiento de tal condición mortal, la cual hace de su ser un lugar radicalmente inhóspito: a cada paso y sin previo aviso, el ser-ahí puede verse desalojado de él, y sabe sin querer saberlo de la continua

${ }^{22}$ La tesis de que toda angustia sería en el fondo angustia ante la muerte, pese a no ser formulada literalmente por Heidegger, se hace evidente en pasajes como el siguiente, donde se dice, respecto a este estado de ánimo: "En ella el ser-ahí se encuentra ante la nada de la posible imposibilidad de su existencia. La angustia se angustia por el poder-ser del ente así determinado y abre de esta manera la posibilidad más extrema. Porque el correr-al-encuentro singulariza al ser-ahí y en esta singularización de sí mismo le hace tener certeza de la totalidad de su poder-ser, a este comprenderse del ser-ahí desde su fundamento pertenece el estado fundamental de la angustia. El ser relativamente a la muerte es esencialmente angustia" (Heidegger 1993, pp. 265 y s.). Esta misma tesis ha sido defendida por Leyte 2005, pp. 133 y s.

Diánoia, vol. LIII, no. 61 (noviembre 2008). 
amenaza de tal posible desalojo. De ahí que Heidegger escriba: "La nada ante la cual nos lleva la angustia desvela la nulidad (Nichtigkeit) que determina al ser-ahí en su fundamento, fundamento que, por su parte, es en cuanto haber-sido-arrojado a la muerte" (Heidegger 1993, p. 308). La nulidad revelada por la angustia se solapa además con lo dado a entender por la conciencia con el silencio de su llamada. Callando, la voz de la conciencia habla del no, de la negatividad intrínseca a su ser en cuanto originaria y constitutivamente destinado a morir. ${ }^{23}$ La vocación de la conciencia exhorta entonces al ser-ahí a apropiarse de su ser mortal, a la asunción de su finitud resultante del correr al encuentro de su muerte. Y puesto que ese movimiento de retorno hacia sí contenido en tal anticipación quedará asimismo ligado a la angustia, tal apropiación de sí acaecerá en medio del silencio.

Es en este punto, una vez mostrada la conexión de los fenómenos de la angustia y la vocación de la conciencia con la finitud del ser-ahí, donde cabe plantear de nuevo la pregunta por el sentido del silencio que ambos momentos involucran o, dicho de otra manera, por las razones de fondo por las que ese hacerse cargo de su muerte aparece asociado a su callar. Para responder a ella, considero especialmente relevante un aspecto del habla introducido por Heidegger en el contexto del análisis de la temporalidad del ser-ahí. En el marco de ese análisis, al que conducirá la determinación de su propiedad, se señala el predominio de un modo específico de temporalización en cada uno de los elementos constitutivos del "ahí" de su ser a excepción del que representa el habla. Pues dado que en ella ocurre la articulación de tales elementos, ningún modo de temporalización puede excluirse de su comprensión. No obstante, Heidegger puntualizará: "Pero, como de hecho el habla se expresa regularmente por medio del lenguaje y dice en primer lugar en el modo de un dirigirse al 'mundo circundante' para hablar de las cosas de las que se ocupa, la presentación tiene en él una función constitutiva preferencial" (Heidegger 1993, p. 349). La función correspondiente a la expresión del habla en la manifestación sonora del lenguaje, esto es, en lo que comúnmente se entiende por hablar, estribaría fundamentalmente en la presentación de aquello sobre lo cual se dice algo, en hacerlo presente por medio de la palabra. Atendiendo a esta especificidad del lenguaje, por un lado, y a la interpretación de la muerte ofrecida por

\footnotetext{
${ }^{23}$ Sintetizamos así el sentido de lo que Heidegger llamará en Ser y tiempo el serdeudor (Schuldigsein) del ser-ahí en tanto carácter ontológico anterior a y condición de posibilidad de todo efectivo estar en deuda o hacerse deudor. Tal ser-deudor se definirá como "el ser fundamento para un ser determinado por un no —es decir, fundamento de una nulidad" (ibid., p. 283).
} 
la analítica existenciaria, por otro, propongo el siguiente interrogante: ¿sería la muerte un fenómeno susceptible de presentación en el lenguaje? ¿En qué medida cabría un hablar sobre ella si ese hablar, en el significado trivial del término, implica una presentación de lo hablado en él?

Ya se ha comentado el rechazo heideggeriano a la determinación de la muerte como un acontecimiento situado al final de la existencia que la clausurara definitivamente. Esta idea trivial de la muerte vendría impulsada por la desaparición de otros entes semejantes al ser-ahí en tanto única experiencia empírica que cabe de ella. Pero la ineficacia de tal experiencia para aprehender la globalidad ontológica del ser-ahí parece quedar fuera de toda discusión en atención a un rasgo del mismo, ya indicado, de esencial importancia en la analítica existenciaria: el ser "en cada caso mía" de la existencia, la relación única e intransferible de cada ser-ahí con su propio ser, según la cual también su muerte le afectaría en su singularidad irremplazable. Desde esta perspectiva, la captación del fenómeno de la muerte en su originariedad exigirá necesariamente su comprensión en términos de una muerte propia, es decir, como mi muerte en cada caso. $\mathrm{Y}$ tal imperativo impugna su posible asimilación al hecho puntual que pondría fin a mi vida, pues que mi muerte tenga lugar conlleva mi propia desaparición y, en consecuencia, su ya no poder ser de ninguna manera fenómeno para mí, o, lo que es lo mismo, su traslación fuera del ámbito fenoménico que me es accesible. Por ello, la muerte concebida como propia no sólo elude toda ubicación en el presente o inscripción en "ahora" alguno, sino que se opone a la noción misma de un presente y a su realidad efectiva. ${ }^{24}$ Según la lectura heideggeriana, la muerte sería, en efecto, una no-presencia, algo ajeno a un presente desde el cual contemplarla en su fenomenalidad. Más allá de la quiebra del concepto tradicional de tiempo que ello supondrá en el trayecto de Ser y tiempo, a partir de este carácter no presencial de la muerte cabe formular la siguiente hipótesis hermenéutica con respecto al silencio del ser-ahí frente a ella: si, como dice Heidegger, el hablar sobre algo, en el sentido de manifestarse expresamente en palabras sobre ello, entraña la presentación de ese algo sobre el cual se habla, la muerte propia destacará justamente como aquello que de ningún modo se deja decir, ya que toda tentativa de decir mi muerte comportaría la pretensión de hacer presente lo que fenomenológicamente nunca puede serlo para mí, esto es, lo que a todas luces se sustrae a mi presencia.

${ }^{24}$ Cfr. Martínez Marzoa 1974, pp. 224-227.

Diánoia, vol. LIII, no. 61 (noviembre 2008). 
El auténtico alcance interpretativo de esta hipótesis se vislumbra atendiendo al lugar que la cuestión de la muerte ocupa en el despliegue de la analítica existenciaria. Al hilo del análisis de la angustia se ha constatado cómo la patencia repentina del haber-de-morir del serahí equivalía a un tiempo a la de su específica condición ontológica de poder-ser o ser-posible, cotidianamente encubierta. Ello deriva del hecho de que en la muerte se localiza la única posibilidad de su ser que en ningún caso pierde su condición de posibilidad, que permanece libre de todo cumplimiento o realización mientras este ente "es". Por su carácter irrealizable y extremo, la posibilidad de la muerte marca en cada caso el límite que define la existencia, el horizonte siempre abierto dentro del cual cualquier otra posibilidad acontece y se manifiesta como tal, pues sólo con ella se accede a la completud o totalidad de su ser, que permite su percepción como el poder-ser global que siempre ya es. Del hacerse cargo de la posibilidad irrenunciable e irrevocable de su muerte dependerá entonces la apropiación de tal poder-ser. Por este motivo, es pertinente decir que la comparecencia del ser del ser-ahí pasa indefectiblemente por la asunción de su desaparición, de su no-ser, en tanto su darse a ver en cuanto tal coincide con su propia retirada o sustracción última. Ahora bien, aceptar esta premisa significa reconocer que aquello que ante la muerte se hace patente no es sólo el no-ser de esta posibilidad última, sino un "no" que traspasa radicalmente la totalidad de su ser: la muerte descubre que, lejos de tratarse de algo presente, el ser del ser-ahí consiste más bien en una no-presencia, en algo que rehuye toda presentación; en definitiva, que la abertura para la presencia de todas las cosas que es su ser no constituye presencia alguna porque ésta, de manera paradójica, únicamente tendría lugar con su dejar de ser.

Retomando aquí la pregunta del porqué del silencio del ser-ahí ante su finitud, la argumentación efectuada legitima la siguiente conclusión: el rehusarse de la muerte propia a la presentación del lenguaje delata en última instancia el ocultamiento o denegación de su propio ser a esa misma presentación, la imposibilidad de someterlo cabalmente al decir si ello implica necesariamente traerlo a presencia; pues, como se desprende de lo antes expuesto, el único decir verdadero sobre él habría de acaecer tras la muerte del ser-ahí, en la completud de su existencia y, por tanto, en el momento en el cual todo discurso por su parte queda absolutamente excluido.

En la dirección abierta por esta hipótesis cabría a su vez interpretar la vinculación esencial que al término de la primera sección de Ser y tiempo — tras haber demostrado la unidad inmanente entre la reso- 
lución resultante del prestar oído a la llamada de la conciencia y la anticipación de la muerte-, Heidegger establece de manera explícita entre el modo de ser de la "propiedad" (Eigentlichkeit) y la ausencia de lenguaje. Frente a la impropiedad cotidiana del ser-ahí y las desfiguraciones que le son inherentes, el concepto de "propiedad" designaría el instante de descubrimiento y apropiación de esa no-presencia de su ser que se acaba de analizar. Se trata además del único momento en que el ser-ahí abandona la impersonalidad y anonimato del uno para pasar a ser "él mismo". En este estado de apropiación de sí, el callar del ser-ahí se torna relevante hasta el punto de que exclusivamente ese silencio parecerá garantizar la mismidad que con ello conquista. Leemos en Ser y tiempo: "El ser-ahí es propiamente él mismo en el aislamiento originario de la callada resolución dispuesta a la angustia. El ser-sí mismo propio no dice, en cuanto silente, 'yo-yo', sino que en el silencio 'es' el ente arrojado que puede ser en cuanto propio" (Heidegger 1993, p. 322-323). Según insinúa este pasaje, el desprendimiento del ser-ahí del dominio cotidiano del uno desembocaría en la renuncia a todo decir sobre sí y sobre aquello que en la angustia se le muestra de sí mismo, como si todo discurso estuviera irremediablemente destinado a falsear esa verdad desencubierta o, cuando menos, expuesto a tal posible falseamiento. No parece trivial, por otro lado, que Heidegger subraye la negativa del ser-ahí apropiado de sí a decir "yo, yo" frente a su constante afirmación por parte del uno impropio. Pues, desde una óptica estrictamente lingüística, ¿no es justamente el yo la instancia del lenguaje que cualquiera puede ocupar al hacer uso de la palabra? ¿No se opondría cualquier enunciación desde el espacio vacío del yo, capaz de acoger a cualquiera que hable, a la irreductibilidad ontológica de la que el ser-ahí, al enfrentarse a su muerte irreemplazable, se ha hecho cargo en la propiedad de su ser? El silencio de la propiedad del ser-ahí semejaría obedecer al reconocimiento de cierta indecibilidad de su ser, de cierta imposibilidad de exhibirlo en el decir a causa de su radical singularidad y de la ocultación que le es inherente.

La cuestión que aquí emerge como fundamento explicativo del callar atribuido al ser-ahí en Ser y tiempo no sería otra que la de la impotencia de la palabra para expresar el ser del ente que somos y, con ella, la de la posible demarcación de los límites del decir en lo relativo al problema del ser. Pero de ser acertada esta explicación, la postura heideggeriana respecto a dicha cuestión aparecería envuelta en una particular ambivalencia: no debe olvidarse que ese callar no se concibe como un modo de ser ajeno al habla, sino, por el contrario, como una modalidad o posibilidad esencial de la misma. En la medida en que Heidegger observa 
que "para poder callar, el ser-ahí debe tener algo que decir" (Heidegger 1993, p. 165), su silencio queda inscrito de antemano en el interior del espacio del habla y no en un ámbito de exterioridad frente a ella: en contraposición al silencio de quien estuviera privado de la capacidad de hablar, el callar de este ente es un callar elocuente, un callar expresivo que dice o da a entender sin hacer uso de discurso alguno. Por otra parte, ello sería coherente con la caracterización heideggeriana del habla en general, en correspondencia con el lógos griego, como un déloun o hacer patente, puesto que el silencio de quien es capaz de hablar también descubre, o muestra, sin necesidad de hacer uso de la palabra. ${ }^{25}$ Como acaba de apuntarse, en ese callar el ser-ahí se daría a entender a sí mismo su propio ser desde el reconocimiento de su carácter no verdaderamente decible o agotable en el discurso. Pero en lo paradójico de la idea de un callar que habla sobre algo al tiempo imposible de decir en palabras cabría leer, además, el justo reflejo de un ser patente en su propio sustraerse, esto es, atravesado por la doblez de ocultarse y a la vez comparecer en su ocultamiento. En definitiva, tal interpretación del callar indicaría que lejos de caer, pese a su indecibilidad, más allá del terreno del habla, el ser se revela precisamente como indecible dentro de una modalidad específica de ésta.

Una objeción importante a la que debe enfrentarse la hipótesis propuesta para aclarar el sentido del silencio en Ser y tiempo procede del hecho mismo de la existencia de esta obra. Afirmar que el callar del serahí sería en el fondo la única respuesta realmente ajustada al descubrimiento del carácter no-decible o no-presentable por medio del lenguaje de su ser supondría reducir al absurdo el propio proyecto de la analítica existenciaria, dado que su aspiración a llevar a cabo una exposición lingüística de la constitución ontológica del ser-ahí, encaminada a la determinación del sentido del ser en general, entraría en franca contradicción con sus propios resultados. Adoptando el enfoque contrario, negar tal carácter contradictorio de Ser y tiempo equivaldría a aceptar que cada uno de los capítulos, de los parágrafos, de las oraciones que componen este texto desmienten la hipótesis de una presunta indecibilidad del ser de este ente: tanto este tratado en particular como el conjunto de la obra heideggeriana invalidarían en principio la explicación sugerida, ya que sus textos serían la prueba fehaciente de la posibilidad de un discurso ontológico sobre el ente que somos. Sin embargo, ciertas reflexiones metodológicas, efectuadas de manera dispersa en el primer periodo de la trayectoria heideggeriana, no sólo no impugnarían la hi-

${ }^{25}$ Cfr. Heidegger 1993, p. 32.

Diánoia, vol. LIII, no. 61 (noviembre 2008). 
pótesis proyectada, sino que vendrían más bien a avalarla. El sentido de tales reflexiones, desafortunadamente nunca desarrolladas de forma exhaustiva por Heidegger y, por tanto, de todo punto insuficientes en relación con la importancia del problema que señalan, radicará justo en la asunción más o menos expresa de las dificultades y el constante riesgo de ontificación, nunca plenamente superable, que encierra cualquier discurso sobre el ser. Como habrá de comprobarse en el siguiente apartado, soslayar tal ontificación exigirá asumir que ni el ser del ente que somos ni el ser en general pueden ser propiamente "dichos" sino únicamente "indicados" (angezeigt), lo cual denotaría cierta incompatibilidad entre la constitución del lenguaje y la pretensión de decir el ser.

\section{El decir filosófico: la cuestión de la indicación formal}

Si Heidegger pone de relieve en Ser y tiempo el carácter eminentemente presentativo de todo lenguaje en cuanto manifestación expresa del habla, el caso más palpable y quizá extremo de tal carácter se encontraría en el enunciado teórico, cuyo objetivo reside en la presentación o exhibición explícita de algo en el conjunto de propiedades que lo conforman. Ello es debido a la estructura misma del enunciado, articulada, como ya vimos, por el "como apofántico". Mientras las cosas emergen en primera instancia desde el contexto significativo del mundo, es decir, gracias a su articulación originariamente hermenéutica, la articulación apofántica derivada de ella involucra su desprendimiento o aislamiento de ese entramado significativo sobre el que reposa su aparición inmediata, así como su determinación no ya en función de éste, sino de aquello que se ofrece a su mera contemplación. Enunciar algo sobre algo para su determinación temática implica entonces mostrarlo desde la perspectiva de lo puramente presente en él, es decir, "enseñar alguna cosa presente en su estar presente de este y de aquel modo" (Heidegger 1976a, p. 158). Pese al carácter derivado asignado al modo de descubrimiento del ente que instaura el enunciado, Heidegger destacará en la etapa de Ser y tiempo que se trata de la única estructura posibilitante de un puro mostrar contemplativo, y por ello necesariamente vigente en toda apropiación teórico-cognoscitiva de lo real. ${ }^{26}$ De ahí que tales proposiciones teóricas o temáticas formen parte esencial del modo de proceder de la ciencia. Pero también se insistirá en que la determinación de algo como algo por medio del enunciar trae consigo la ocultación de su específico carácter de ser, dependiente de su articulación hermenéu-

${ }^{26}$ Cfr. Galzacorta 2006, p. 321.

Diánoia, vol. LIII, no. 61 (noviembre 2008). 
tica. Dice Heidegger: "Si algo se tematiza de tal modo que el con-qué (Womit) del trato pasa a ser el acerca-de-qué (Worüber) de un enunciar determinante, entonces con ello retrocede el verdadero carácter de ser, por ejemplo, de la tiza, que queda nivelada a mera cosa" (Heidegger 1976a, p. 158). Arrancada del para-qué que permite su comparecencia primaria y de la red de referencias en que éste se inserta, la tematización conlleva la determinación de la cosa exclusivamente en función de los rasgos puramente presentes en ella, esto es, de las propiedades puestas de manifiesto por el enunciar predicativo. ${ }^{27}$ Todo aquello que, siendo constitutivo de su aparecer, carece de tal modo de presencia en la propia cosa, como sería el caso de la red significativa del mundo, queda velado en el enunciado, que así encubre su carácter ontológico original.

De acuerdo con la reducción a mera presencia, que según su análisis opera la articulación apofántica, Heidegger se planteará abiertamente en estos años la cuestión acerca de cómo efectuar proposiciones sobre el ser del ente que somos sin que éste resulte encubierto o desfigurado por el propio proceder enunciativo. $\mathrm{Si}$, al igual que cualquier ciencia, también la ontología fundamental comporta una aproximación teórica o temática encaminada a la determinación expresa y cognoscitiva de su objeto de estudio, a diferencia de ellas tal objeto no se localiza en cosa alguna, sino en el ser. Frente al discurso óntico de la ciencia, Ser y tiempo acomete la elaboración de un discurso ontológico, que es aquél que se pregunta por en qué consiste ser. ${ }^{28}$ Más en concreto, en esta obra se interroga por el ser del ente que somos y su sentido, siempre en vistas a la dilucidación del sentido del ser en general. Pero, como se ha visto, ni el ser de este ente específico ni, por lo que se acaba de decir en relación con la articulación apofántica, el de ningún otro ente, se dejan considerar desde la óptica de la presencia. Lejos, por tanto, de circunscribirse al ser del ser-ahí, el problema acerca de cómo decir el ser afecta a toda ontología en general. Más aún teniendo en cuenta que esa reducción a pura presencia producida por el "como apofántico" vendría ligada a la propia objetivación u ontificación del ser solidaria del surgimiento del pensar filosófico, a partir del cual el

${ }^{27}$ En este mismo contexto añade Heidegger: "A través de la tematización de lo que originariamente es objeto de uso en tanto cosa meramente presente, el carácter original de ser del objeto, de la tiza, es ocultado a su vez en la medida en que ya no existe inmediatamente como utensilio, sino como mera cosa presente en la que yo constato una propiedad y se la atribuyo, de modo que en la propia atribución determino la cosa" (1976a, p. 159).

${ }^{28}$ Cfr. Martínez Marzoa 1985, p. 13.

Diánoia, vol. LIII, no. 61 (noviembre 2008). 
ser será concebido como entidad (Seiendheit) y ésta como mera presencia. ${ }^{29}$ Por eso, Heidegger afirmará en la obra de 1927 que para la tarea de captar el ente en su ser "faltan no sólo en la mayoría de los casos las palabras, sino ante todo la 'gramática'" (Heidegger 1993, p. 39). ${ }^{30}$ Pues del examen efectuado del enunciado se desprende que el uso de proposiciones teóricas en la analítica existenciaria para expresar sus logros conduciría necesariamente a la ocultación de aquello mismo que se pretende sacar a la luz, esto es, a la exhibición del ser del ser-ahí justamente como aquello que no es, como algo meramente presente, y, en consecuencia, a la propia inviabilidad de dicha analítica existenciaria. ${ }^{31}$

El método que Heidegger utilizará en estos primeros años de su trayectoria para evitar, si bien nunca de manera plena ni definitiva, esa objetivación del ser estribará en la comprensión del decir filosófico en términos de lo que designa como una "indicación formal". Algunos de los textos escritos y cursos impartidos entre 1921 y 1930 introducen esta fórmula para afirmar que todos los conceptos filosóficos, así como todos los enunciados sobre el ser o el sentido del ser del ser-ahí, tendrían el carácter de indicaciones formales o serían formalmente indicadores. ${ }^{32}$ En la interpretación de esta noción anida uno de los focos de

${ }^{29}$ Como Heidegger comenta poco antes de Ser y tiempo: "Debido a que para los griegos, tanto para Platón como para Aristóteles, la diferencia entre el enunciado categorial y el enunciado sobre lo mundanamente presente quedó oculta, y a que todos los enunciados se comprendieron directamente como enunciados sobre el mundo, sucedió que el ser mismo, tan pronto vino a la mirada, fue concebido como un ente" (Heidegger 1976a, p. 410, n. 1). Según se sostiene en este pasaje, la ontificación del ser aparecería, por tanto, como consecuencia de la propia tematización del ser con que se inicia la filosofía.

${ }^{30}$ A este respecto, Coriando ha señalado que la ausencia de una gramática apropiada para expresar el ser más allá del modelo de la presencia tendría su origen en el hecho mismo de su concepción como algo meramente presente: "Pero la 'gramática' de una determinada lengua histórica no es una legalidad autónoma situada 'fuera' de la respuesta (explícita o no explícita, liberadora o desfiguradora) que en cada caso se haya dado a la 'cuestión del ser', sino que corresponde siempre ya al respectivo habérselas con el ser y mantiene todo 'es' en su apertura, previamente decidida, de una manera u otra. Si falta la 'gramática' para la liberación del ser del poder del presupuesto de la presencia, es porque el pensar occidental concibió el ser exclusivamente como entidad y éste como mera presencia" (Coriando 1998, p. 29).

${ }^{31}$ Cfr. Dahlstrom 1994, pp. 777 y s.

${ }^{32}$ Así, en el citado curso del semestre de invierno de 1925-1926 se declara: "Todos los enunciados sobre el ser del ser-ahí, todas las oraciones sobre el tiempo, todas las oraciones dentro de la problemática de la temporalidad, tienen, en tan-

Diánoia, vol. LIII, no. 61 (noviembre 2008). 
mayor controversia de la investigación dedicada a la filosofía heideggeriana más temprana, probablemente porque, como se ha mencionado, ninguna de sus apariciones se encuentra acompañada de explicaciones suficientes para entenderla plenamente ni para constituirse en una metodología propiamente dicha. ${ }^{33}$ A pesar de que la realización de un estudio mínimamente pormenorizado de esta cuestión desbordaría los límites establecidos por la temática de este trabajo, intentaré una aproximación a aquellos aspectos más estrechamente relacionados con el motivo de nuestra investigación.

En el curso que imparte en Friburgo en el semestre de invierno de 1921-1922, sin duda el marco donde con más prolijidad desarrolla la cuestión de la indicación formal, Heidegger identifica de manera explícita lo formalmente indicado con el "ser". ${ }^{34}$ Ello explica el vacío o ausencia de contenido que, según se dice, denota el término "formal" en esta expresión, a diferencia de toda posible remisión a lo material contingente o a lo eidético: la vacuidad de la indicación formal se cifra en que, en lugar de procurar la presentación de un ente u objeto, con ella se apunta a su ser. Por otra parte, la atribución a lo formal de tal vacuidad de contenido responde a su intrínseca referencia a la indicación, ya que sólo como algo vacío puede lo formal poseer un carácter indicador. Este carácter se explica en este contexto como la mostración o prefiguración de un camino, de una dirección a seguir, de manera que la comprensión de la indicación formal consistiría en dirigir la mirada hacia lo formalmente indicado por ella. ${ }^{35}$ Como Heidegger advierte: "el contenido, las determinaciones dadas del objeto, no deben convertirse en tema en cuanto tales, sino que el comprender captador ha de seguir la dirección de sentido indicada" (Heidegger 1985, p. 32). En tanto indicaciones formales, los conceptos de la filosofía no pueden aprehender estrictamente el ser o englobarlo en su contenido semántico, ni aspiran,

to que proposiciones expresadas, el carácter de la indicación" (Heidegger 1976a, p. 410). La idea se repite alrededor de 1930, último momento en que menciona la cuestión de la indicación formal, no ya con respecto a los enunciados sobre el ser del ser-ahí o su sentido, sino a los conceptos filosóficos en general: "Todos los conceptos filosóficos son formalmente indicadores y sólo cuando son tomados así dan la auténtica posibilidad del concebir" (Heidegger 1992, p. 425).

${ }^{33}$ Cfr. Dahlstrom 1994, p. 779.

${ }^{34}$ Cfr. Heidegger 1985, p. 61. Sobre la íntima conexión entre la indicación y la cuestión ontológica, que atraviesa la historia de la metafísica atestiguando una fractura en el lenguaje entre el plano del mostrar y el de decir, entre la indicación y la significación, pueden encontrarse sugerentes observaciones en Agamben 2002, pp. 35-39.

${ }^{35}$ Cfr. Heidegger 1985, p. 34. 
por ello, a hacerlo presente: sólo lo señalan, lo indican, dan la dirección a seguir para su captación sin captarlo propiamente ellos mismos. Tampoco se trata de que el ser se hallara al final del camino apuntado por la indicación formal. El modo de acceder a él residiría más bien en el propio movimiento de alejamiento del ente, de arrancarse de las cosas, que supone el seguimiento de ese camino. Por esta razón, Heidegger adjudicará a la indicación formal una función defensiva, de rechazo (abwehrend) o incluso "prohibitiva", ${ }^{36}$ en tanto su objetivo radicará sobre todo en desviar o apartar la mirada de la interpretación habitual y dominante del ser, llevada a término desde el supuesto de la mera presencia. Esta idea será elaborada con más detalle en el último de los cursos donde se menciona el asunto de la indicación formal, que data del semestre de invierno de 1929-1930. La incapacidad de los conceptos filosóficos para captar el ser se vinculará aquí expresamente tanto al carácter no-presencial del ser-ahí como a su estricta singularidad.

Para clarificar la diferencia entre los conceptos puramente científicos y los filosóficos, cuyo rasgo fundamental se emplaza de nuevo en su carácter formalmente indicador, Heidegger propondrá en este curso recurrir al problema de la muerte. Recordando algunos de los rasgos fundamentales del análisis del "ser relativamente a la muerte" del serahí efectuado en Ser y tiempo, se constata la usual tendencia a entender el correr al encuentro de la muerte correspondiente a la propiedad de la existencia como un constante pensar en la muerte. El fundamento de tal interpretación se hallaría en cierta actitud, según Heidegger fundamental y adoptada de forma inmediata, que ubica lo verdaderamente ente, lo que verdaderamente "es", en lo constantemente presente, y anima a considerar la referencia del ser-ahí a su muerte en función de tal noción de presencia. Heidegger subraya entonces el carácter no-presencial no sólo de la muerte, sino de la plena dimensión que representa el ser-ahí, para declarar que los conceptos que permiten acceder a él "solamente son comprensibles cuando no son tomados como significados de propiedades y dotaciones de algo meramente presente, sino como indicaciones para que el comprender se desprenda de las concepciones comunes del ente" (Heidegger 1992, p. 428). En calidad de indicaciones formales, los conceptos de la filosofía intentarían alejar la comprensión del ser, en este caso del ser-ahí, de la idea de la sola presencia, apartándola de esa actitud fundamental que reduce el ser al ente sin percatarse de la diferencia existente entre ambos. Pero en este contexto se añade, además, que la incapacidad de tales conceptos para aprehender el ser

${ }^{36}$ Cfr. Oudemans 1990, pp. 88 y 99.

Diánoia, vol. LIII, no. 61 (noviembre 2008). 
del ente que somos procedería no sólo de su divergencia y exterioridad con respecto al ámbito de lo presente, sino también de su radical singularidad. Tal y como se aduce, la peculiaridad de los conceptos de la analítica existenciaria estriba en que "apuntan al ser-ahí. Pero el serahí es siempre - como yo lo entiendo- mío. Porque mediante esta indicación apuntan según su esencia en cada caso a una concreción del ser-ahí singular en el hombre, pero nunca la pueden llevar en su contenido, son formalmente indicadores" (Heidegger 1992, p. 429). En el "ser en cada caso mía" de la existencia se localiza un nuevo obstáculo que impide que los conceptos aplicados al ser-ahí alcancen, en su inevitable generalidad, a dar cuenta de su ser, e impone su contemplación en tanto indicaciones formales. ${ }^{37}$ Sin embargo, Heidegger se mostrará asimismo perfectamente consciente de la posibilidad de tergiversar dicho carácter indicador de los conceptos filosóficos si se los entiende según el contenido semántico que siempre y ya de antemano poseen. Y puesto que tampoco la gramática de las oraciones de la ontología fundamental diferirá de la de cualquier otro enunciado apofántico, la tendencia fundamental a pensarlos desde la perspectiva de la mera presencia no podrá ser nunca eliminada de manera definitiva. ${ }^{38}$

A pesar de que la cuestión de la indicación formal no se agota con la caracterización realizada, sí considero que ésta puede bastar al menos para resaltar aquellos aspectos que de modo más directo la ligarían a la temática del silencio. Acabamos de ver cómo, en lo concerniente a la constitución ontológica del ser-ahí, las razones aportadas por Heidegger para justificar esa función meramente indicadora del decir filosófico coinciden precisamente con aquellas que justificaban el callar de este ente en la propiedad de su existencia, a saber, la falta de presencia de su ser y su radical singularidad. En este sentido, podría afirmarse que aquello que fuerza al ser-ahí al silencio es la causa de una cierta ambivalencia atribuible a las proposiciones de la filosofía, fruto de su dificultad para comunicar el ser: aun situándose en el ámbito de la manifestación puramente lingüística, el decir filosófico configura un decir incompleto, un decir que, lejos de significar propiamente, debe conformarse con indicar. De esa precariedad deberá por fuerza hacerse cargo la filosofía como única vía legítima para superar, aunque nunca de forma concluyente, el peligro de ontificar el ser. Pero el hecho de que ni tal exigencia, ni tampoco el grado de autoconciencia que requeriría,

\footnotetext{
${ }^{37}$ Agamben ha señalado que ya Aristóteles habría apuntado a esta cuestión al ligar la esencia primera o individuo singular a la esfera del pronombre demostrativo, de función más indicadora que semántica. Cfr. Agamben 2002, p. 36.

${ }^{38}$ Cfr. Coriando 1998, p. 31.
} 
puedan ser reclamadas al decir trivial, al tiempo que sin ellas toda expresión sobre el ser conduciría — dada la articulación y estructura del enunciado- a su reducción al ámbito de lo ente, es lo que, a nuestro juicio, tornaría relevante el silencio del ser-ahí. Fuera del ámbito de la filosofía y de su reflexión teórica sobre la posibilidad de decir el ser, la única opción del habla que en esta etapa de la trayectoria heideggeriana parecería quedar libre de encubrirlo sería la representada por la modalidad del callar. La existencia de un decir filosófico sobre el ser no resultaría entonces incoherente, sino más bien complementaria respecto a éste: en el silencio del ser-ahí en tanto modalidad específica del habla ante la verdad de su ser, por un lado, y en la parcialidad e incompletud del decir filosófico, por otro, habitarían diferentes formas de reconocimiento de aquella ambivalencia o duplicidad por la que el ser, sólo manifiesto en su ocultamiento, quedaría inevitable pero problemáticamente entrelazado con el hablar.

Bajo el signo de esa doblez o duplicidad, patente de maneras distintas en el decir trivial y el decir filosófico, tendrá lugar lo que a nuestro entender marcaría el siguiente paso en la trayectoria heideggeriana para pensar la cuestión del silencio y de los límites del decir que le es inherente. Dicho paso se localizará en su atención, iniciada poco después de la publicación de Ser y tiempo, por un tercer ámbito del lenguaje diverso tanto del decir trivial como del filosófico, y que será el decir poético. Ello derivará a su vez de una focalización más directa del problema del lenguaje, así como de determinados cambios en el modo de interrogar por él, que sobrepasarían en cierto sentido el terreno del ser-ahí. Para cerrar este trabajo se esbozan algunas de las cuestiones más importantes planteadas en los años posteriores a Ser y tiempo en relación con el tema que nos ocupa.

\section{La pregunta por la esencia del lenguaje: el decir poético y la cuestión del lógos}

Pese a que el análisis efectuado ha pretendido subrayar el lugar central que ya desde la etapa de Ser y tiempo se concede al lenguaje en la configuración ontológica del ser-ahí y en la elaboración de la pregunta por el sentido del ser, no será hasta 1934 cuando Heidegger dedique un curso a este tema y formule de manera explícita la pregunta por la esencia del lenguaje. ${ }^{39}$ Tanto en éste como en otros escritos surgidos en estos

\footnotetext{
${ }^{39}$ Nos referimos al curso impartido en el semestre de verano de ese año precisamente con el título Logik als die Frage nach dem Wesen der Sprache.
} 
años, la condición necesaria e ineludible del lenguaje en la abertura al ser del ente que somos, ya vigente pero no acentuada con la debida claridad en 1927, se afirma con contundencia hasta el punto de declararse que "el lenguaje es lo primero que lleva a lo abierto a lo ente en tanto que ente", de modo que "donde no se despliega esencialmente ningún lenguaje, como en el ser de la piedra, la planta y el animal, tampoco existe ninguna patencia del ente". ${ }^{40}$ Afirmaciones de esta índole deben inscribirse, por otra parte, en el marco de los comienzos del tan discutido "vuelco" o "giro" (Kehre) experimentado por el pensamiento heideggeriano aproximadamente hacia 1930. Brevemente, cabe decir que éste consistiría en un cierto cambio de perspectiva por el que la constitución ontológica del ser-ahí pasa a pensarse, no ya como punto de partida para analizar el juego de mostración y retirada que articula el aparecer de las cosas, sino en función de él. Ese giro no alterará en lo esencial la relación establecida en 1927 entre el ser y el hombre, ya que el lugar donde acaece la abertura por la cual las cosas se muestran seguirá emplazándose en el ser del ente que somos. Pero sí es cierto que, por su causa, el lenguaje habrá de perder su carácter existenciario y su tematización lo vinculará de manera directa a la pregunta por el ser, ahora denominado con expresiones como el "ser mismo" o la "verdad del ser". Dentro de ese cambio de perspectiva, una de las diferencias más obvias con respecto a la posición de Ser y tiempo en lo relativo a la cuestión del lenguaje se halla en que la emergencia explícita en 1934 de la interrogación por su esencia dirigirá su respuesta más allá del lenguaje cotidiano o trivial hacia el ámbito de lo que Heidegger llamará, en un significado específico del término, el decir poético o el poema. No es casual, además, que la construcción del sentido de tal poetizar, identificado con un lenguaje originario cuya esencia quedaría encubierta en el desgaste y las ocultaciones propias del lenguaje cotidiano, ${ }^{41}$ se ligue

${ }^{40}$ Esta cita procede de la conferencia de 1935 "Der Ursprung des Kunstwerkes" (Heidegger 1994c, p. 61). Esta idea aparece también, entre otros, en el texto de 1936 "Hölderlin und das Wesen der Dichtung", donde dice: "El lenguaje no es sólo una herramienta que el hombre posee también entre muchas otras, sino que sólo el lenguaje otorga la posibilidad de estar en medio de la abertura del ente. Sólo donde hay lenguaje hay mundo" (Heidegger 1996, p. 38).

${ }^{41} \mathrm{Al}$ término de este curso se lee: "La esencia del lenguaje no se pone de manifiesto allí donde éste ha sido desgastado y aplanado, tergiversado y forzado a convertirse en medio de comunicación y en pura expresión de la así llamada interioridad. La esencia del lenguaje se despliega esencialmente allí donde éste acontece como potencia creadora de mundo, es decir, allí donde el lenguaje prefigura de antemano el ser del ente y lo lleva a articulación. El lenguaje originario es el lenguaje del poetizar" (Heidegger 1998, p. 170). 
indisolublemente a la figura de un único poeta: Hölderlin. Su poesía será por vez primera abordada en el curso siguiente al mencionado y, como demuestran el conjunto de textos escritos por Heidegger sin intención de proyección académica entre 1936 y 1940, su interpretación jugará un papel esencial tanto en la consolidación del giro como en el "pensar de la historia del ser" (seingeschichtliches Denken) inaugurado en esos años. ${ }^{42}$

La cuestión de las razones por las cuales tal caracterización del poetizar vendría de la mano de la obra de Hölderlin y no de cualquier otro poeta merecerían en sí mismas un estudio aparte. Por eso, sólo indicaremos que en dicha obra acontece una confrontación sin precedentes con Grecia, capaz de poner de relieve la dimensión o abertura cuya pérdida u olvido da lugar a la Modernidad. Ahí se descubre, además, una distancia insalvable, una radical diferencia entre ambos momentos de cuya asunción dependerá nuestra propia autocomprensión como modernos. ${ }^{43}$ Del complejo entramado de temas que a partir de aquí cabría desplegar, nos interesa destacar cómo ese reconocimiento de lo específicamente moderno que se produce en Hölderlin queda reflejado, para Heidegger, tanto en la tarea que asigna a su poetizar como en el modo de llevarla a término. Al hilo de la lectura de los himnos tardíos Germanien y Der Rhein ensayada en este primer curso sobre Hölderlin, Heidegger emplazará el rasgo esencial del lenguaje poético, contemplado desde el punto de vista de su potencialidad expresiva, en el hecho de que "este lenguaje no debe precisamente expresar, sino más bien debe dejar lo indecible (das Unsagbare) como no-dicho (ungesagt), y precisamente en y a través de su decir". ${ }^{44}$ Lo peculiar del lenguaje poético

${ }^{42}$ Heidegger llegará en estos años a identificar a Hölderlin con "el poeta del otro inicio de nuestra historia venidera" (Heidegger 1997, p. 426) frente al primer inicio acaecido en Grecia, y declarará que la historicidad del tránsito del primer al otro inicio "está decidida a través de la palabra de Hölderlin" (Heidegger 2005, p. 149).

${ }^{43}$ Para una interpretación del sentido de la obra de Hölderlin, que toma como suelo la lectura que Heidegger proyectó, remitimos a Martínez Marzoa 1992. Un estudio más pormenorizado de los motivos que animan la reflexión heideggeriana sobre la obra del poeta puede encontrarse en Allemann, 1954.

${ }^{44}$ Cfr. Heidegger 1999, p. 119. La idea expresada por este pasaje se presentará en diferentes momentos de la interpretación heideggeriana del poetizar. Así, en un curso posterior sobre Hölderlin, Heidegger se preguntará retóricamente: "Pero, ¿debe todo aquello que es dicho ser también pronunciado? ¿No debe quizás ser callado aquello que realmente hay que decir? ¿De qué otra manera podría, sin embargo, ser callado, sino en lo dicho?" (Heidegger 1993, p. 132). Y nuevamente, en una conferencia mucho más tardía, concretamente de 1968, se dice: "Callar; ¿significa 
se hace girar en torno a la relación establecida en él entre el decir y lo indecible: en y por medio de lo dicho, el decir poético habrá de hacer patente algo que, en su condición indecible, al mismo tiempo se sustrae al propio decir; sin poder pasar al plano de lo dicho, lo indecible deberá mostrarse en el decir precisamente como no-dicho. El lenguaje poético se concibe así como el lugar de aparición de un indecible cuyo salir a la luz requiere, paradójicamente, de ese mismo decir.

A pesar de que en el contexto inmediato de este fragmento no se determina de forma explícita a qué remite tal indecible, tanto de la totalidad del desarrollo del curso como de otros escritos cronológica o temáticamente próximos a él se desprende con claridad su asimilación al ser, en esta etapa designado también con el arcaísmo Seyn. Heidegger tomará dicho arcaísmo directamente de los escritos teóricos de Hölderlin, el cual habría de referirse más tarde a él en algunos de sus poemas con la expresión die Natur. Para Heidegger, la tarea del poetizar estriba en decir el ser, aun cuando ese decir se traduzca, en contraste con el quehacer filosófico, en un nombrar lo sagrado. ${ }^{45}$ Pero en íntima conexión con la cuestión de que en la poesía de Hölderlin se revele "el tiempo de la huida de los dioses", a la abertura o diferencia aludida con el término ser le será esencial su propio ocultarse, su no-presencia, y por tanto, la imposibilidad de ser dicha de manera inmediata. No obstante, frente al silencio o callar del decir trivial ante tal ocultamiento enfatizado en Ser y tiempo, el decir poético asumirá ahora la tarea de poner de manifiesto aquello que se oculta en su mismo ocultarse, esto es, de exponer en su lenguaje su propia indecibilidad.

Ahora bien, ¿de qué modo puede y debe lo indecible en cuanto tal hacerse patente en el propio decir? Una vez señalado que el objetivo del canto reside en desvelar, en volver relevante esa abertura originaria por la que acaece la presencia del ente, Heidegger añade: "Pero si el poetizar es grande y auténtico, entonces fracasará en ello necesariamente. Pero precisamente de esta manera, en la más alta pasión del más estricto querer decir, llega a topar abruptamente con lo indecible (das Unsagbare)" (Heidegger 2005, pp. 234 y s.). La comparecencia de lo indecible en el decir exige así que el canto se proponga, emprenda el camino del querer decirlo para, sin embargo, fracasar en su empeño e iluminar a través de ese fracaso tal carácter indecible. Por ello, y pese

eso solamente no decir, permanecer mudos? ¿O sólo puede verdaderamente callar quien tiene algo que decir? En ese caso callaría en suprema medida quien fuera capaz de dejar aparecer en su decir, y precisamente sólo mediante éste, lo no-dicho (das Ungesagte), y precisamente en cuanto tal" (Heidegger 1996, pp. 188 y s.).

${ }^{45}$ Cfr. Heidegger 2005, pp. 159 y s. 
a su imposibilidad, el poetizar no puede eludir el intento de decir el ser, que debe acometer con el fin de que su fracaso lo descubra en su propia ocultación. En otras palabras: el frustrarse del intento de decir el ser significará la forma misma de su desencubrimiento, si bien dicho desencubrimiento sólo implicará la mostración de su constitutivo rehusarse. ${ }^{46}$ La doblez o ambigüedad advertida, por un lado, para el decir trivial, cuyo callar se definió como una modalidad del habla y, por otro, para el decir filosófico en su carácter formalmente indicador, aparecerá aún con más claridad en el decir poético como reflejo de la propia doblez del ser, consistente en comparecer en su propia retirada, en exhibirse en el decir a través de su no ser dicho.

Pero junto a la reflexión sobre ese ámbito del decir poético, en estos años comienza a observarse otra divergencia esencial respecto al planteamiento de Ser y tiempo que irá imponiéndose en los venideros: la traslación de la cuestión del callar, del silencio, desde el ser-ahí al propio ser. El callar de este ente será retrotraído a lo presentado como el silencio o incluso silenciamiento (Verschweigung) del ser mismo, silenciamiento que vendría a expresar su intrínseco ocultamiento en el ámbito del decir, y en el cual, además, se situará el origen y fundamento de la esencia del lenguaje. ${ }^{47}$ Ello justifica que años después de Ser y tiempo Heidegger llegara a reinterpretar la voz de la conciencia examinada en la analítica existenciaria como la "voz silenciosa del ser", de la cual el hombre se hace eco a través de su lenguaje y su pensar. ${ }^{48}$ Sin embargo, no puede olvidarse que, incluso en su silencio, el ser constituye algo dicho, algo cuya manifestación únicamente acontece en el propio decir, de manera que la condición silente del ser deberá entenderse también desde su inmanente vinculación a aquél. Por este motivo, la respuesta a la pregunta por la esencia y origen del lenguaje se dirigirá a partir

\footnotetext{
${ }^{46}$ Aunque sin citar explícitamente a Heidegger, Martínez Marzoa parece asumir este aspecto de su interpretación de Hölderlin al afirmar: "nos hemos referido a una poesía, la de Hölderlin, cuyo carácter es el de la imposibilidad. Quizás esto sea (incluso tautológicamente) carácter de todos aquellos poetas que están por encima de toda valoración y de toda crítica. Hölderlin se pone siempre y en cada caso a hacer precisamente aquello que no se puede hacer, y se pone a ello precisamente para no-poder hacerlo; dígase, si se quiere, 'para fracasar' " (Martínez Marzoa 1992, p. 99).

${ }^{47}$ Tal y como Heidegger declara a principios de los años cuarenta: "al ser no pertenecería sólo el ocultamiento, sino que el ocultamiento tendría una referencia destacada con respecto al "decir" y éste sería el silenciamiento (Verschweigung). Entonces el ser sería el silenciamiento de su esencia [...] el ser sería, como el silenciamiento, el origen del lenguaje" (Heidegger 1981, p. 64).

${ }^{48}$ Cfr. Heidegger 1976 b, pp. 306 y s. y 310.
}

Diánoia, vol. LIII, no. 61 (noviembre 2008). 
de los años treinta no sólo al terreno del decir poético, sino a aquello que, en referencia a Heráclito, Heidegger denominará el lógos o el Decir (Sage) en cuanto instancia inseparable del hablar humano, pero no reductible a él. Como esencia del lenguaje, el desplegarse de ese lógos será identificado con el "son del silencio". ${ }^{49} \mathrm{Al}$ anunciarse, resonando, en el propio lenguaje, el silencio al que aquí se apela quedará de nuevo íntimamente entrelazado con el hablar. Una vez más, la doblez en que se cifra el ser, el abrirse originario por el que las cosas se dan a ver a costa de su ocultación, se dibujará en ese pliegue o doblez entre el sonar y el silencio que es para Heidegger el lógos. Lógos que, en su irreductibilidad al lenguaje humano, tampoco se dejará capturar en enunciado alguno. ${ }^{50}$

\section{BIBLIOGRAFÍA}

Agamben, Giorgio, 2002, El lenguaje y la muerte. Un seminario sobre la negatividad, Pre-textos, Valencia.

Aler, Jan, 1972, "Heidegger's Conception of Language in Being and Time", en Joseph J. Kockelmans (comp.), On Heidegger and Languaje, Northwestern University Press, Evanston, pp. 33-62.

Allemann, Beda, 1954, Hölderlin und Heidegger, Atlantis, Freiburg.

Coriando, Paola-Ludovica, 1998, "Die 'formale Anzeige' und das Ereignis. Vorbeitende Überlegung zum Eigencharakter seinsgeschichtlicher Begrifflichkeit mit einem Ausblick auf den Unterschied von Denken und Dichten", Heidegger Studien, vol. 14, pp. 27-43.

Dahlstrom, Daniel, 1994, "Heidegger's Method: Philosophical Concepts as Formal Indication", Review of Metaphysics, vol. 47, pp. 775-795.

Galzacorta, Íñigo, 2006, "Mundo, cosa y enunciado: Heidegger y la pregunta por el ser", Ontology Studies/Cuadernos de Ontología, 5/6, pp. 319-326.

Greisch, Jean, 1987, La parole heureuse. Martin Heidegger entre les choses et les motes, Beauchesne, París.

Heidegger, Martin, 2005, Über den Anfang, G.A. 70, Klostermann, Fráncfort.

—, 2002, Grundbegriffe der aristotelischen Philosophie, G.A. 18, Klostermann, Fráncfort.

—_, 2001, Unterwegs zur Sprache, Neske, Stuttgart.

__ , 1999, Hölderlins Hymnen "Germanien" und "Der Rhein”, G.A. 39, Klostermann, Fráncfort.

__, 1998, Logik als die Frage nach dem Wesen der Sprache, G.A. 38, Klostermann, Fráncfort.

—_, 1997, Besinnung, G.A. 66, Klostermann, Fráncfort.

${ }^{49}$ Esta formulación se encuentra, por ejemplo, en la conferencia de 1950 titulada "Die Sprache" (cfr. Heidegger 2001, p. 30).

${ }^{50}$ Cfr. Heidegger 2001, p. 266. 
Heidegger, Martin, 1996, Erläuterungen zu Hölderlins Dichtung, Klostermann, Fráncfort.

—_, 1994a, Beiträge zur Philosophie. Vom Ereignis, G.A. 65, Klostermann, Fráncfort.

__ 1994b, Heraklit: Logik. Heraklits Lehre vom Lógos, G.A. 55, Klostermann, Fráncfort.

—_, 1994c, Holzwege, Klostermann, Fráncfort.

__, 1993, Sein und Zeit, Niemeyer, Tubinga.

__, 1992, Die Grundbegriffe der Metaphysik. Welt - Endlichkeit - Einsamkeit, G.A. 29/30, Klostermann, Fráncfort .

__, 1986, Nietzsches metaphysiche Grundstellung im abendländischen Denken. Der ewige Wiederkehr des Gleichen, G.A. 44, Klostermann, Fráncfort.

—, 1985 , Phänomenologische Interpretationen zu Aristóteles, G.A. 61, Klostermann, Fráncfort.

__, 1981, Grundbegriffe, G.A. 51, Klostermann, Fráncfort.

__ 1979, Prolegomena zur Geschichte des Zeitbegriffs, G.A. 20, Klostermann, Fráncfort.

__, 1976a, Logik. Die Frage nach der Wahrheit, G.A. 21, Klostermann, Fráncfort.

— , 1976b, Wegmarken, G.A. 9, Klostermann, Fráncfort.

Herrmann, Friedrich-Wilhem von, 1985, Subjekt und Dasein, Klostermann, Fráncfort.

Hübner, Alfred W.E., 2001, Existenz und Sprache. Überlegungen zur hermeneutischen Sprachauffassung von Martin Heidegger und Hans Lipps, Duncker und Humblot, Berlín.

Imdahl, Georg, 1997, Das Leben verstehen. Heideggers formal anzeigende Hermeneutik in den frühen Freiburger Vorlesungen (1919 bis 1923), Königshausen und Neumann, Würzburg.

Jaeger, Hans, 1971, Heidegger und die Sprache, Francke, Munich.

Kockelmans, Joseph. J., 1972, "Language, Meaning and Ek-sistence", en, J.J. Kockelmans (comp.), On Heidegger and Language, Northwestern University Press, Evanston, pp. 3-32.

Leyte, Arturo, 2005, Heidegger, Alianza, Madrid.

Martínez Marzoa, Felipe, 1992, De Kant a Hölderlin, Visor, Madrid.

_ 1985, El sentido y lo no-pensado (Apuntes para el tema "Heidegger y los griegos), Secretariado de Publicaciones de la Universidad de Murcia, Murcia.

—_, 1974, Iniciación de la filosofía, Istmo, Madrid.

Martínez Matías, Paloma, 2005, "Propiedad e impropiedad en Ser y tiempo", Pensamiento. Revista de Investigación e información filosófica, no. 231, pp. 395-420.

Oudemans, Theodor C.W., 1990, "Heideggers 'logische Untersuchungen'”, Heidegger Studien, vol. 6.

Sallis, John, 1970, "Language and Reversal", The Southern Journal of Philosophy, vol. 8, no. 4, pp. 381-397.

Diánoia, vol. LIII, no. 61 (noviembre 2008). 
Stenstad, Gail Marie, 1988, Heidegger's Question of Language: From Being to Dwelling, U.M.I Dissertation Information Service, Ann Arbor.

Vandevelde, Pol, 1994, Etre et discours. La question du langage dans l'itinéraire de Heidegger (1927-1938), Académie royale de Belgique, Gembloux.

Wohlfahrt, Günter, 1994, "Das Schweigen. Philosophische Bemerkungen zum Begriff des Schweigens bei Kierkegaard, Nietzsche, Heidegger und Wittgenstein", Prima Philosophia/Sonderheft, pp. 63-78.

Recibido el 4 de mayo de 2007; aceptado el 21 de noviembre de 2007. 